\title{
What is in the Dash? An Examination of the Life and Contributions of John B. Flege, Jr., MD
}

\author{
Walter H. Merrill, MD \\ Department of Cardiac Surgery, Senior Associate Chief of Staff, Vanderbilt University Hospital, Nashville, Tennessee
}

It is, indeed, a privilege to stand here before you this morning to give the annual Flege Lecture. Dr. Sande Starnes has kindly supplied me with a list of prior visiting professors, who previously have had the honor to deliver this talk. When we examine the names of those who have been so honored, and note their many accomplishments, I cannot help but remember the words of Winston Churchill, who, when speaking of another person, could well have been speaking of me, when he described "a modest little person, with much to be modest about."

It is particularly noteworthy that we are gathered this morning in the surgical amphitheater of what was formerly known as the Cincinnati General Hospital. It has been wonderfully restored and updated. As my late friend and former colleague, Dr. Bob Bower noted, this is the site that was chosen by Dean Christopher Holmes for the dedication ceremony of the newly completed hospital, and it was the place that the keys to the hospital were given to the Mayor of Cincinnati.

\section{INTRODUCTORY REMARKS}

It is truly an honor to offer some remarks this morning. Today, a story will be told. You might ask, why? Abraham Verghese tells us that, "Stories are instructions for living and are the way we make sense of our lives. We are never in more need of them than now." Through storytelling, we "find community, we renew the faith, we are reassured. We are not alone."

The title of this story is, "What is in the Dash?" This might seem like an odd title for a surgical grand rounds. One may ask, what relevance could this possibly have? To what does it refer? Have you noticed that people are typically drawn into contemplation about someone's past life by focusing on their birthdate and their date of death? Certainly, these two dates are important, as one can get some context about a person's life by considering the decades in which they lived and died, and by relating the decades to other important events, such as the war in Vietnam, 9/11, etc. However, it seems that a much more interesting way of going about this is to consider, what is in the dash? In other words, to examine in detail the life that was lived and to consider the lessons we can hope to learn from it.

To the best of my ability the story of the life lived by the late John B. Flege, Jr., M.D., will be told (Figure 1). His story is quite remarkable, and the lessons we might glean from his life should be remembered, for our everlasting benefit. Perhaps it

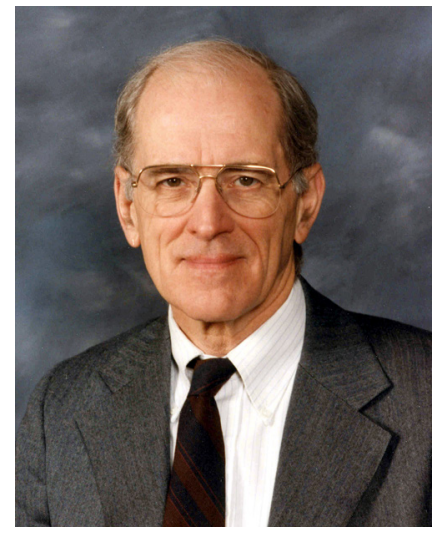

Figure 1. John B. Flege, Jr., MD

is safe to say that many of those who practice surgery currently and those who practice in the future will, no doubt, continue to be influenced by the lessons learned from his extraordinary life and career. For further emphasis on the possible benefits of a study of the past, consider the words of William $\mathrm{H}$. Welch, the first Dean of the Johns Hopkins University School of Medicine, who said this, "Nothing adds more to the interest and fascination of our profession than the study of the historical and cultural background of medicine and the natural sciences through the ages, and I venture to add that such study helps to make better teachers and better doctors."

From 2002 until 2009, and thereafter, John served capably as my colleague, friend, and mentor, and I owe him and Allison Flege an immense debt of gratitude for all that they did for me. In preparation for this talk, background materials kindly were provided by Allison and their daughter, Elizabeth Burns. These were supplemented by the Winkler Center archives, Steve Wiesner and the late Roger West, and several of his former associates.

\section{BOYHOOD AND HIGH SCHOOL}

John was born on May 10, 1929, in Williamstown, KY. He was one of six children. It is probable that he acquired his affinity for education and teaching from his father, who was, at one time, a high school teacher and coach, and from his grandfather, who also was a teacher. One of his early associates, Dr. Joe Todd, would say that "We shared an agricultural background with parents that valued education." 
He was sometimes hungry and cold as a young boy, during the depression. He went to school in Williamstown before he was enrolled in Mason Consolidated Schools in the middle of the fourth grade. He said of this time that "there never was any homework assigned." According to his transcript, he was, at best, an average student in high school from 1943 to 1947. This was a small school in the hills of Kentucky, with a total of about 60 students. During his high school years, John played on the basketball team.

Following graduation, he did not know what to do, so he answered an ad in the newspaper to work in Covington as a cooper, or barrel maker. He concluded that this was dangerous and hard work. He left that job, went back home, and worked on a local farm for the rest of the summer, baling hay and working on a tractor. This, too, was hard and hot work, but at least he did not consider it to be so dangerous. Along came August, and he thought about going to college, but he had no money to pay for it, neither did he have any particular plan as to a proposed course of study.

\section{ACADEMIC PURSUITS AND RESIDENCY TRAINING}

What John did have was an incredible work ethic and an appreciation for opportunity. His Uncle Charles loaned him money to go to college. He also worked part-time as a road service worker for a garage. He says he fixed flat tires by riding around the county in a Jeep with a tank of compressed air and a bunch of tools. He discovered that the government was offering scholarships for future doctors in the post-World War II era, so, sensing an opportunity, he decided to go into medicine. It was at about this time that he developed his life-long attitude that served him so well: "Do whatever you stumble into - just do it well." He went to the University of Kentucky and apparently his intellectual fires were turned on, as he graduated with high distinction, and he was inducted into Phi Beta Kappa.

From there, he enrolled in medical school at the University of Cincinnati. He graduated in 1954, where he excelled once more. He was third in his class and Vice President of his class, and he was inducted into Alpha Omega Alpha. John was an instrument tech in the operating room. He also had a part-time job at night in an emergency room, suturing lacerations.

Following medical school, he became a rotating intern at Cincinnati General Hospital. He performed very well, according to those who were evaluating him. From there, he spent a year as Assistant Resident in Surgery at Ohio State University Hospital. Next, from 1956-1958, he served as a General Surgeon and Captain in the U.S. Air Force, first in Thule, Greenland, and subsequently at Westover Air Force Base, Massachusetts. He again demonstrated much promise. Following completion of his military service, he went to Europe to "goof off." He bought a one-way ticket on a cargo ship. After traipsing around Europe, John met Allison on the return voyage home. She had been in Germany for three years and traveled around Europe on a motorcycle. He continued to date Allison, and they eloped and were married in
Port-Au-Prince December 28, 1960. Quite by accident, they bumped into a friend of John's from the military, Ira Rothfeld, and he served as the best man.

From 1959 to 1963, he served as Assistant Resident and Chief Resident at the Cincinnati General Hospital. During that period, surgery residents routinely were assigned to rotate to the Holzer Clinic in Gallipolis. Dr. Holzer had this to say about John in a letter to Dr. Altemeier, who was Department of Surgery Chair at the time, "He is quite competent technically, has been very diligent in the care of his own patients and in taking an interest in the preoperative and postoperative courses of our patients, as well as adding a good deal to the care at the operating table. He is quiet, of course, as you know, but he has gotten along very well with the people here. We would certainly rank him as being among the best of the men we have had from Cincinnati."

As an example of his intellectual curiosity, John studied French when he was a resident in surgery. John took evening classes for three years, when his schedule permitted. He recognized that in studying French he would achieve a much better understanding of the English language.

He would later say of his time as a surgery resident under Altemeier, "We managed to work together despite it all. He didn't give me grief. When I would need a recommendation, he always supplied it, but in muted tones." John also added, in a moment of self-reflection, "He didn't give me the adoration that I thought I was due, either."

One of the first papers he wrote had to do with the surgical management of atrial septal defects. He said that "Writing did not come easily for me. The idea of writing a paper was not exciting to me. In my early schooling, writing was not part of the program." And, to show how far things have come, he added, "I neglected to learn typing. That is a big regret. When I was in school, typing was for girls."

When he was about to finish his general surgery training, Dr. Altemeier wrote a letter of recommendation. It is summarized as follows, "He is a safe surgeon with considerable potential for further development." John spoke with Altemeier about a possible faculty appointment with the department, but he was offered only a research position in surgical bacteriology, which he declined.

\section{ON TO ENGLAND}

Following completion of training at Cincinnati General, John was interested in thoracic surgery, but he felt that he needed more training before he could practice independently, particularly in cardiac surgery. A faculty member at Children's Hospital, Dr. Samuel Kaplan, knew the people at Hammersmith Hospital in London, and he suggested that John could find additional training there. He spent two years, 1963-1965, as a Senior Registrar with Mr. Cleland and Mr. Bentall. His clinical training was supplemented by investigative work, which included studies on the design of mitral and aortic valve prostheses. John would say of his time in the lab, "About 10 years later, somebody came out with a bi-leaflet aortic valve based on the same principle as the one he had 
designed. That valve has been the one most commonly used for the past 30 years. I probably could have made a case for patent infringement had I patented the design."

While serving as a senior registrar at Hammersmith, John had an interesting experience one day while walking down the hallway. He said, "I saw all of Ian Aird's collected papers and operative movie reels, headed for the rubbish bin. It was just in a huge pile waiting for the trash man. It made me sad to see it, but I had no place to keep all of this stuff. Who knows what sort of treasures were in that heap? That just impressed me. I still remember it today. It seemed like there was so much potential in that heap. The new guy needed some space for an office, so he just had all of the contents of Aird's office shoveled out into the dump. That's the way it goes." He again wrote to Dr. Altemeier inquiring about a faculty position, but he was denied one.

\section{FIRST JOB AT IOWA}

After finishing his training in London, John became Assistant Professor of Surgery at the University of Iowa. He had a quite varied practice there doing adult and congenital heart surgery primarily, as well as general thoracic surgery. He was interested in problems of malformations of the mitral valve, mitral valve replacement with autologous fascia lata, tracheoesophageal fistula, surgical repair of various congenital heart malformations, and repair of complications of acute myocardial infarction. An example of early recognition of his ability, and of his potential for having a major influence on future developments in cardiac surgery, comes from a letter dated April 21, 1967, by George Gorsuch, MD, "After knowing you for many years, and reflecting on your intelligence and ability, and after reading your letter concerning your invitation to Children's Hospital in Cincinnati to perform a plastic repair of a mitral valve, I am moved to say that you will be among the greats or near greats of cardiovascular surgery in due course."

While at Iowa, John volunteered for two months as a surgeon on the hospital ship, Project Hope, in 1967 in Colombia and again in 1968 in Sri Lanka. While on these two tours, he frequently engaged in his most favorite activity, which was the teaching of learners of all types.

\section{NEW BEGINNING IN CINCINNATI}

On September 24, 1967, he wrote to Dr. Altemeier that he was approaching a plateau in Iowa, and he was ready to consider opportunities elsewhere. His thoughts are summarized as follows, "So far my salary has been adequate, but I started earning too late in life to be satisfied with the prospects in the future. The birth of our third child and first son last month accentuates this point." Altemeier responded that he really had no faculty position for him at the University of Cincinnati.

It was at about this time that John Fenton, MD, of Christ Hospital, wrote the 1968 Annual Report of the Department of Special Examinations of Christ Hospital. In it, among other things, was a description of future plans. It said, "The development and function of the cardiac catheterization laboratory is extremely dependent on the development of openheart surgery at the Christ Hospital. While the Division of Cardiology will of course not be performing the surgery, this program is of such importance to our Division that we will be very actively involved in helping a cardiac surgeon initiate his work and in supporting his endeavors, should such a program be approved and begun by the Board of Directors and by the Administration." Shortly thereafter, a proposal for the development of cardiovascular surgery at The Christ Hospital was put forward. It said, "The unanimous opinion of the members of the Executive Committee of the medical staff, and of their invited guests of October 29, 1968, was that any Cardiovascular Surgery Program developed by The Christ Hospital must be of extremely high quality." There was general agreement that a surgeon from outside Cincinnati would have to be attracted, as the mortality and morbidity rates for cardiac surgery in the city were unacceptably high.

In John's files, there is a letter of reference from Robert Tidrick, MD, to John Fenton. It says, "He has a keen mind. He is perceptive, well read, critical of sources of information, independent in judgment and inclined to his own counsel. He is methodical, orderly, systematic and thorough ..." Later, he added, "I think John can run an independent program, get good results, work harmoniously with people with whom he is associated and make contributions to cardiac surgery. I have high regards for him personally, for his standards and ideals."

In another letter from Lewis January, MD, it states that "He is a solid thinker with an innovative mind, and I believe all of us in cardiology here, without exception, consider him an excellent surgeon. I think that he shows excellent judgment and is technically accomplished."

There is a handwritten note by John dated February 23, 1969, which states, "Talked by phone with Dr. Larrick at 2 pm and confirmed that I would take the job." Thus, history was about to be made. John subsequently moved to Cincinnati with his family, began preparations for cardiac surgery at The Christ Hospital, and started clinical work in September. Dr. Fenton would write in December 1969, "With Dr. John Flege, a cardiac surgeon of exceptional quality, directing the program, a very auspicious start has been made. Since actual open-heart surgery was started in early September, 1969, over a dozen cardiac procedures have been performed on severely ill patients. To date, there has been only one mortality."

John continued in solo private practice until Dr. George Callard joined him in 1971, with Dr. Joe Todd joining in 1973. The practice grew to five by 1977. In addition to his appointment as Director, Department of Cardiac Surgery, The Christ Hospital, John was appointed Director, Division of Cardiac Surgery, The Jewish Hospital in 1978. Dr. David Melvin joined the practice in 1979. As an example of the tremendous growth in cardiac surgery services, there were 13 cardiac cases at The Christ Hospital in 1969, 228 in 1975, and 556 in 1979. Early on, an electronic database was established to keep track of the cases.

John's typical characteristics of restlessness and easy descent into boredom are revealed in an interesting letter 
from 1973 in which he states, "Allison and I just returned from a two-week vacation, most of it being spent on the beach in South Carolina. For a while, the rest was refreshing, but I soon got tired of doing nothing."

In his later reflections, he stated that "I made pretty frequent trips to Europe for meetings and to work in other hospitals ... So, then I would go visit and work with him (Mr. Geoffrey Smith) and back and forth for several years. A week or two at a time. It was easy to work together in those days. They have so many regulations now, you can't do that."

John also was very interested in maintaining contacts with surgeons he had met at Hammersmith and elsewhere in Europe. In addition to his work in London, he traveled intermittently to all areas of the globe to learn from others. He became an active member of the Society of Cardio-Thoracic Surgeons of Great Britain and Ireland, the International Cardiovascular Society, and the European Society for CardioThoracic Surgery. He also had a great interest in innovation, and he was constantly looking for ways to advance cardiac surgery through collaboration with industry, through mentoring junior associates, and by thinking of improvements in the methods of surgical operations and new developments in alternative and minimally invasive techniques throughout his career. Many of these advances were published in the usual academic journals. Later, he would say, "I am always searching for a better way to do things. You must stimulate intellectual curiosity before you can be truly innovative."

In 1979, John began having residents from the University of Cincinnati rotate with him at the Christ. Of this time, he said, "Beginning the first of February, we have a resident in thoracic and cardiovascular surgery from the University for the next three months. Dr. Altemeier has indicated that this is a trial period, so whether it will be continued beyond that I really don't know."

\section{THE UNIVERSITY OF CINCINNATI}

In 1982, John was appointed as Professor of Clinical Surgery at the University of Cincinnati, and he was made Director of the Division of Thoracic and Cardiovascular Surgery. This appointment was orchestrated through the assistance of the Dean, Dr. Robert Daniels, and it was done over the resistance of the chair of the Department of Surgery, Dr. Josef Fischer. John and his associate, Dr. George Callard, did all of the early cardiac operations at the university. They were highly successful, with the first 90 procedures being done without mortality, which was a truly outstanding accomplishment at the time. John held this post until 1987. Maintaining an interest in the training of residents, he reestablished an ACGMEapproved residency in Thoracic Surgery. He would later say, "We never had a heart surgery program at the University that was successful. It had been tried four times between the late " 50 s and early ' 80 s. There was the problem of deficient infrastructure and institutional support." He would add, "... we became interested in adding heart transplant to the mix. Dr. Melvin had a particular interest in pursuing this. He devoted virtually his entire effort to laying the groundwork for it.
After a few months, during which time we went away a few times to take courses at other institutions and did some work in the animal laboratory, then we announced we were ready to open for business." He added, "It (the first heart transplant) was a big event, according to the news media. For us, it didn't seem like all that much. Even though it was the first time we had done it, it already seemed like routine because our planning had been very good and effective."

In 1986, he would write, "We have now done 22 transplants in 21 patients, and 20 patients are surviving. We are doing the complete management of the patients." By now, John had been asked to establish the cardiac surgery program in northern Kentucky at St. Elizabeth, and he would add "Our Kentucky unit has developed nicely, with an average of four cases a week ... The University remains fairly static, and there is continuing conflict between the Department Chairman and myself."

\section{LEAVING THE UNIVERSITY OF CINCINNATI}

The conflict basically had to do with John's continued ties to his private practice group, which John believed were essential. A protracted series of discussions was undertaken between John, Dr. Joseph Fischer, Dr. Donald Harrison, and Dean John Hutton, leading to the resignation of John. His letter of December 28, 1987, to Dean Hutton stated, "I feel a profound loyalty to my school, and am loathe to abandon it." He added, "I take some satisfaction in having established a somewhat successful cardiac surgery program in an institution where there never had been one, and regret that I could not have left it in more stable condition."

It was after this time that John again manifested restlessness and boredom. After he left the University, he was not very busy at Christ, so he thought about going to graduate school. His thoughts turned to a master's program in history, but he did not have an undergraduate degree in history. Then, he thought about law school. He said, "I have always been interested in systems. I think a lot about what makes things work and why they don't work. The law emerged to bring order into society. I thought that would be of interest." He signed up for a Kaplan LSAT review course, took the test, and he enrolled in UC law school in 1989. He says, "By and large, the classwork was pretty interesting, I thought. There were two other guys about my age enrolled." He went to law school year-round, while continuing to operate regularly, and graduated in three years. He said that he "concluded that practicing law wouldn't be a whole lot of fun. Verbal skills have never been my strong point. I thought it would be an interesting hobby. I did take the bar exam and got my credentials. I do the continuing education each year. Just for a hobby."

\section{THE TAKE HOME LESSON}

If anyone has not been paying attention before, you should do so now. What follows is the primary take home lesson that is applicable to all surgeons under all circumstances. John 
offers a precise summary of his thoughts, regarding the obligations of a surgeon to his patients in a letter he wrote in January 1990. The final version of the letter says, in part, "It is my contention that an experienced surgeon who has given some thought to the subject (that is, when to operate on a patient with acute myocardial ischemia) is a better judge of what an operation should consist of, when it should be done, what it might accomplish, and what its risks are, than is a cardiologist.

The surgeon has a conflict of interest. His personal gain depends upon agreeing with the cardiologist and proceeding accordingly even though a different action based on his own surgical experience and knowledge may be in the patient's best interest. The cardiologists exert a powerful influence over the surgeon's decisions and activities by controlling the referral of patients.

I believe that the patient needs all the help that he can get. He needs the best reasoned opinion and participation in his management from those working in different disciplines that are relevant to his problem unfettered by concerns about their personal gain. If he gets less, he has misplaced his trust.

I still hold to the archaic notion that the patient's interests come first, and I think that I have been more successful than had I been driven by greed and a lust for power; at least I have a clearer conscience."

\section{MORE HONORS, TRIPS TO SWEDEN}

In May 1994, at the UC Reunion Banquet, Dr. Flege received from Dean Hutton the Distinguished Alumni Award. Then, in 1995, he received the American Heart Association's Samuel Kaplan Visionary Award.

In 2000, he was appointed Visiting Surgeon at University Hospital in Umea, Sweden for three months. He went back twice more to participate in cardiac surgery and to learn in depth about the Swedish system of healthcare.

\section{A HIGHER CALLING}

In October 2001, the cardiac surgeons at University Hospital left abruptly, and several individuals reached out to John to see if he would come back to perform cardiac surgery and become Acting Chief of the Division of Cardiac Surgery. In an October 29, 2001 email to Dr. Jeff Matthews, the Chair of the Department of Surgery, he stated, "I am willing to proceed with or without the approval of my associates so long as conditions are conducive to real achievement. I am not interested in an exercise of futility. I am interested in enhancing my legacy." He would add in a subsequent email, "This would not endear me to my colleagues but would be consistent with my past practice of going for what I think is the best and letting the chips, or should we say slings and arrows, fall where they may." Two patients were operated upon initially, they both did well, and John's involvement with the University of Cincinnati cardiac surgery program was thus renewed. The heart transplant program, which he initially had a large part in founding, was maintained through the assistance of one of the cardiac surgeons from Children's, Dr. Jeff Pearl.

On November 17, 2001, John wrote in an email to Matthews, "My personal preference is to work with the residents, not that they are of uniform ability, but they are worth investing time and effort in since they are moving up the ladder ... I believe that the residents must be made part of the team and given increasing responsibilities as they develop and in turn they buy in."

It cannot be overemphasized that he was willing to go against the will of his private practice group and come over to work in the University setting. At that time, the practice had an average of eight or nine surgeons working daily at six different hospitals in the city, performing roughly 2600 cases per year.

John laid out his raison d'être in a letter to Matthews in May 2002. He stated that "I have long dreamed that my alma mater would be prominent in the world of cardiac surgery, and I am willing, eager, and in my own opinion, able to do whatever I can to move it in that direction. I do not have a lot of time left, maybe a couple of years, but if I can help the Division achieve prominence, I will feel that my career has been productive, and that there will be some atonement for my failure to move it ahead back in the "80s."

In 2002, John endowed a chair to support the Division of Cardiothoracic Surgery (Figure 2). It was formed with a rather specific agreement as to how the money derived yearly from the chair would be used to support expenditures in the division for educational purposes and other matters. In his typical fashion, when planning for a celebration of the chair was underway, he said, "I realize that some ceremony about the chair is inevitable, but I hope that the hoopla can be minimized. Neither Allison nor I are much into that. I think it more fitting that the attention be focused on the future of the program." Later that year, he returned to the University on a full-time basis as Professor of Surgery. In 2004, a training program in Cardiothoracic Surgery was accredited and began training residents. He would later say, "I derived much satisfaction in participating again in

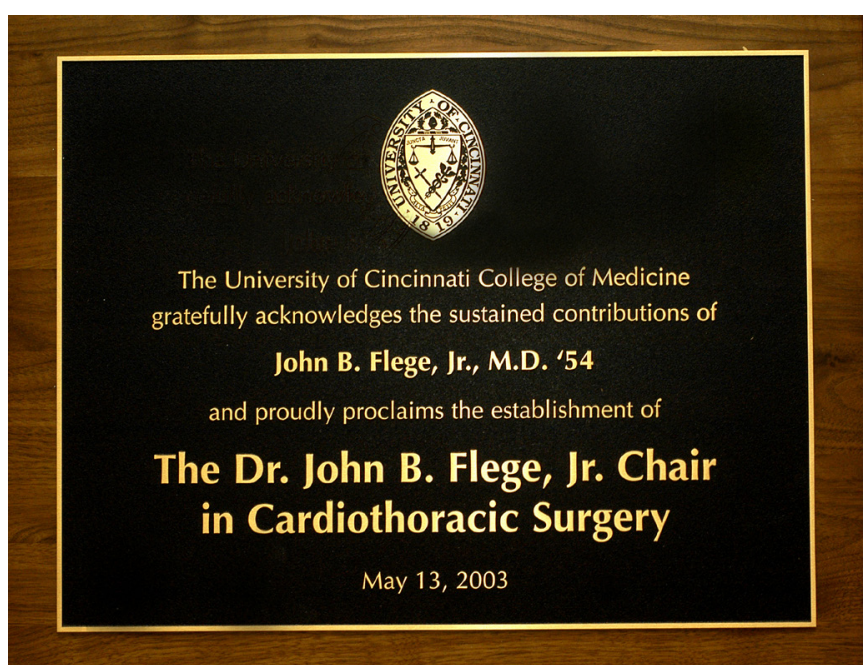

Figure 2. Plaque commemorating the establishment of the John B. Flege, Jr. Chair in Cardiothoracic Surgery at the University of Cincinnati. 


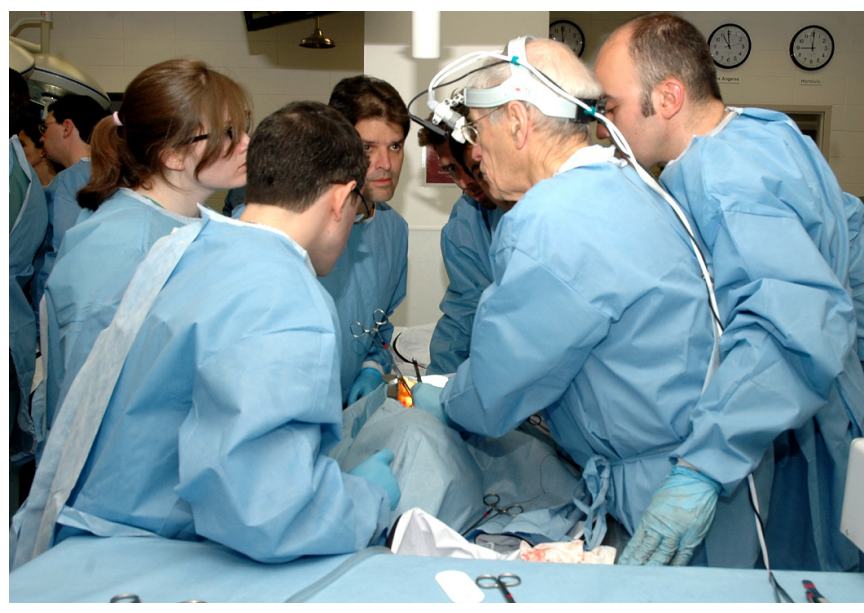

Figure 3. John B. Flege, Jr., MD, seen teaching in the simulated operating room during a session of the Cardiothoracic Surgery Symposium held in Cincinnati, $\mathrm{OH}$.

the training of residents after a long hiatus."

In 2004, John received the first Distinguished Surgeon Award from the Cincinnati Surgical Society. In 2006, he was awarded the Lifetime Achievement Award from the Cincinnati Business Courier. With his usual modesty, he had this to say about the award: "I just want to be remembered for doing a decent job." It is noteworthy that he also was nominated for the Daniel Drake Medal, the highest honor for a graduate of the University of Cincinnati.

It was at about this time that he became co-director of a two-week undergraduate program for aspiring medical students called the Summer Surgery Experience. He was also named the co-editor of a new journal, Innovations, for the International Society for Minimally Invasive Cardiothoracic Surgery. In addition, he was one of the inspirations for the founding of an annual three-day national symposium for residents named the Cardiothoracic Technology Symposium. Once again, this allowed him to perform his favorite activity, which was teaching (Figure 3).

Another example of his effectiveness as a teacher comes from an unlikely source, the Peanuts character Charlie Brown. A greeting card was given to him by a third year UC medical student who had just finished a two-week rotation on the cardiac surgery service as a part of her surgery clerkship. The student said, "I wanted to express my appreciation for your patience and kindness these past two weeks in my first exposure to surgery. Many times, I felt like "Dr. Fumbles," but I am so happy to be given the chance to suture and help in the surgery itself ..." Importantly, she noted, "You have been an inspiration to me and certainly have broken down stereotypes I had of surgeons in general. It truly has been a privilege to work with you, Dr. Flege."

\section{APPROACHING THE LATTER STAGES OF A CAREER}

Quite late in his career, somebody once asked him, "How long are you going to continue working?" His answer was, "I have not worked since I left the farm. It never occurred to me in the early years that I would get paid for what I was doing because it was so much fun!"

John maintained many of his interests outside of the practice of surgery. In a letter written in 2013, he reveals many of his concerns about the future direction of the country. He stated, "The typical American will soon be an obese man or woman sitting in a casino and wearing a couple of pistols and smoking a joint." To this statement he would add, "Changes in the delivery and economics of healthcare are gradually unfolding. Basic medical care is still unavailable to one-sixth of our population." He also said, "Unemployment is falling. I am skeptical that will be sustained. We are so linked with the global economy that unless that improves, I don't see us in the clear."

In 2015, John was named Emeritus Professor. Also, that year he was given the honor to be named as one of two Distinguished Alumni by the Grant County Schools Education Foundation.

John died on March 22, 2018, at the age of 88. Thus, the light was extinguished in a truly brilliant and inspiring individual. His dash, which had included so many life adventures and so many accomplishments, had finally come to an end.

\section{FINAL THOUGHTS}

When reflecting on the experience of his early days as a surgeon, John would say that he had ridden a wave on innovation that was unparalleled and that he was fortunate to be in the right place at the right time. He added, "I finished my training in 1965 , just before coronary bypass surgery burst upon the scene. The evolution of cardiac surgery during my career has been nothing short of fantastic. What was complete fantasy at its beginning is reality now." He would add, "Particularly in the early years of cardiac surgery, things really weren't well established or defined. There was not anybody around that you might say was the penultimate teacher. There was no one that had acquired the knowledge to be a competent teacher of cardiac surgery because the knowledge did not exist. It had not been defined or discovered." He would also say, "What I, and many other surgeons of that era did, was we worked out these problems on an ad hoc basis. The people around us that we had to interface with had various skill sets. We could sit down and have an exchange of ideas and develop the knowledge. We had a common goal, which was better patient care. There was tremendous collaboration."

He lamented the loss of the will to share by members of the profession, which he witnessed later in his career. He said, "Now it is different. People seem to spend a lot of time with self-promotion. There is a lot of economic competition for various treatments. Sometimes, the best option does not prevail. There are a lot of political and economic factors these days."

John was truly an amazing, multitalented individual, with an incredible sense of humor. He exhibited focus and drive and a desire to succeed that was unparalleled. A little-known 
fact is that he was quite generous toward what he considered to be worthy causes, and he quietly assisted others with demonstrated potential that could not otherwise be realized, including payment for the expenses of education, medical care, and housing. Much of his focus was derived from his memories of poverty and a dislike for bureaucrats, and he had a strong desire to make a difference in the world.

In closing, let us return to the beginning, back to where we started, in this very amphitheater. Listen carefully to the words of my late friend, Dr. Bower. In his paper on The Role of Surgical Amphitheaters in Surgical Education in the United States, delivered before the Halsted Society, he stated that "the amphitheater may serve as a reminder of the proud teaching tradition of surgeons. It should remind us that in those places where the Professor, (in this case, Dr. John
Flege), demonstrates to the undergraduate students by teaching and example respect for the patient, a spirit of inquiry and a love of learning, students will want to follow in our footsteps." May it forever be so.

Thank you very much for your time and kind attention. It has been my distinct pleasure to remind you of the many facets and major contributions of Dr. John Flege, and I am delighted to return to this department to tell his story. Thank you again.

\section{FLEGE MANUSCRIPT ACKNOWLEDGEMENT}

This text is based, in part, on a presentation given before the Department of Surgery of the University of Cincinnati on October 6, 2021. The occasion was the annual Flege Lecture. 